\title{
Editorial \\ Tuberculosis: la re-emergencia de un olvido
}

\author{
Andrea Luna Heine
}

La Tuberculosis está entre las 10 principales causas de muerte en el mundo y continúa siendo la primera causa infecciosa por un solo agente. En el 2016, la 0MS estimó 10.4 millones de casos y 1.7 millones de muertes, con un 10\% en promedio de coinfección TBVIH (paciente con tuberculosis y portador de Virus de Inmunodeficencia Humana, VIH), un 4,7\% de multidrogoresistencia (MDR); con una notificación de casos estimados que apenas supera el $60 \%$, donde la migración y refugiados aportaron un tercio de los casos existentes a nivel global. En la Región de Las Américas, en 2016 se estimaron 273.574 casos y 17.033 muertes, $11 \%$ de coinfección TB-VIH y un 2,96\% de MDR; el 69\% de los casos se concentraron en cinco países (Brasil, Perú, México, Haití y Colombia) y la mayor brecha entre casos estimados y notificados ocurrió en tres países (Brasil, Perú y México). Respecto de la situación en Chile, éste pertenece al grupo de países de baja prevalencia, aunque su sostenida tendencia a la baja se estabiliza y quiebra en el 2014. El 2016 reportó 2.548 casos y estimó 279 muertes en 2015, el 64\% de los casos de TB pertenecen a grupos vulnerables (adultos mayores, migrantes, alcohólicos y coinfectados TB-VIH, son los cuatro grupos que concentran el $50 \%$ de casos), la MDR se mantiene en niveles bajos y no hay casos de TB extensamente resistente.

Los ambiciosos objetivos y plan de trabajo de la estrategia "Fin a la Tuberculosis" enunciados en la 67a Reunión Mundial de la Salud en 2014, fijó como meta lograr una reducción de $90 \%$ de las muertes por TB y $80 \%$ de reducción de la tasa de incidencia para el 2030. Los países para cumplir estos objetivos, si quieren superar las brechas entre los logros proyectados y alcanzados, deben adecuar sus lineamientos estratégicos: optimizando los aspectos técnicos del programa, fortaleciendo una respuesta coordinada públicoprivada, así como intersectorial; incorporando nuevos fármacos; reforzando la investigación y asegurar en forma sostenida y protegida parte de los, siempre escasos e insuficientes, recursos que manejan las autoridades políticas para salud. Lo enunciado anteriormente, permite comprender por qué las TB Extra Pulmonares, entre las cual se encuentra la TB cutánea, y cuya importancia epidemiológica no es relevante en el logro de los objetivos mundialmente asumidos por los gobiernos, no se encuentren especialmente relevadas en los Programas de Control; solo se recogen a nivel global como una cifra agregada del total de casos, sin existir lineamientos y recursos específicos para su abordaje y manejo. Sin embargo, en la medida que los países asientan programas exitosos y mejoren sus indicadores epidemiológicos, las Tuberculosis Extra Pulmonares irán cobrando relevancia, representando entre un $10 \%$ a un $25 \%$ de los casos totales por esta enfermedad (la TB cutánea un 1 a 2\%).

El diagnóstico de las TB cutáneas no es nada sencillo, tiene variadas formas de presentación clínica. Algunas de ellas pueden ser similares a las causadas por otras

${ }^{1}$ Dermatóloga y salubrista, Especialista en tuberculosis, Profesor agregado Departamento de Dermatología de la Universidad de Chile, Hospital Clínico San Borja Arriarán.

Correspondencia: Andrea Luna Heine

Email:amlh2009@gmail.com 
patologías, y una de sus variantes clínicas ser expresión de éste u otros posibles agentes. Además, debemos sumar la dificultad técnica de lograr un diagnóstico certero; en muchas ocasiones, por la estrecha ventana de oportunidad diagnóstica para encontrar o lograr viabilidad de este microorganismo que en muestras cutáneas, con excepciones, son muy paucibacilares; o simplemente por la imposibilidad de acceso a recursos de alto rendimiento como el cultivo rápido u otros métodos moleculares aprobados por OMS. Tampoco debemos olvidar por otra parte, la connotación social de esta enfermedad, que en ocasiones hace que el médico se abstenga o sea reticente a realizar el diagnóstico de TB cutánea no confirmada, sólo con elementos de apoyo clínico, especialmente cuando se trata de algunas formas de presentación crónica o larvada, que no comprometen funcionalidad, calidad de vida o mortalidad, quedando así subdiagnosticadas y sin tratamiento.

En la actualidad la globalización y la migración están facilitando, cada vez más, la coexistencia de perfiles epidemiológicos, demográficos y económicos al interior de los países y otros sub-territorios, lo que nos obliga a tener en mente que las personas se trasladan con sus contextos y así debemos abordarlos: poniendo especial énfasis en una buena anamnesis actual y remota. Debemos estar abiertos a incluir en los diagnósticos diferenciales nuevas patologías, que antes eran infrecuentes en Chile, especialmente las infecciosas. Respecto de las Micobacterias, los dermatólogosen Chile debemos prepararnos para encontrar más casos de TB cutánea (aumento de incidencia, migración envejecimiento poblacional, guetos de vulnerabilidad social, uso en aumento de inmunosupresores potentes, mayor acceso a técnicas diagnósticos, etc.), más casos de lepra (principalmente importados y formas paucibacilares), y muy poco o ningún aumento de otras micobacteriosis cutáneas, especialmente las oportunistas, puesto que Chile mantiene un ambiente inhóspito que limita el reservorio ambiental para muchas de estas. Sin embargo, el cambio climático en un mediano futuro podría afectar esta realidad.

En conclusión, en Chile no debemos olvidar la TB y otras Micobacterias en nuestros diagnósticos diferen- ciales. Hacer lo posible por acceder a un diagnóstico de certeza y no tener resquemor de diagnosticar y tratar casos no confirmados bacteriológicamente, si es que contamos con una sumatoria de otros elementos de apoyo diagnóstico al juicio clínico y con histopatología sugerente. Además, es esencial mantener una buena y estrecha relación con los broncopulmonares referentes del Programa de TB en nuestros Servicios de Salud, para acceder a un manejo interdisciplinario y fluido de estos casos, así se puede evitar que muchos pacientes queden a la deriva o se pierdan en esta compleja red de referencia y contrarreferencia de pacientes que requieren acceso al uso de fármacos protegidos.

\section{BiBLIOGRAFÍA}

1. "Tuberculosis" Informe de situación Chile: 2016http://diprece. minsal.cl/wrdprss_minsal/wp-content/uploads/2017/06/Informede-Situaci\%C3\%B3n-de-Tuberculosis-2016.pdf

2. Informe Mundial sobre tuberculosis OMS 2017

3. The end TB strategy: Main indicators in the Americas, Pan American Health organization 